\title{
Habilidades del pensamiento creativo asociadas a la escritura de textos multimodales. Instrumento para su evaluación en la Educación Básica Primaria
}

\author{
Creative Thinking Skills Associated to the Writing of Multimodal Texts. \\ An Instrument for its Assessment in Primary School \\ Habilidades do pensamento criativo associadas à escrita de textos \\ multimodais. Ferramenta para sua avaliação na educação básica primaria \\ Dora Inés Chaverra-Fernández ${ }^{1}$ \\ Claudia del Carmen Gil-Restrepo ${ }^{2}$
}

Resumen

El estudio que aquí se reporta ${ }^{3}$ tiene un carácter exploratorio y fue desarrollado a partir de una metodología mixta con estudiantes de quinto grado de una institución educativa rural. Tiene como propósito general contribuir al uso pedagógico de las tIC en la Educación Básica Primaria mediante la indagación de las habilidades del pensamiento creativo y la escritura de textos multimodales. El artículo se enfoca en la presentación de los resultados relacionados con: a) el diseño y la validación del instrumento para evaluar las habilidades del pensamiento creativo vinculadas a la escritura de textos multimodales; b) la asociación existente entre estas dos variables; y c) la posibilidad de potenciar este tipo de pensamiento en la escuela mediante actividades de escritura digital intencionadas, representativas y transversales al currículo escolar.

\section{Palabras clave}

Pensamiento creativo, escritura multimodal, didáctica, TIC, educación primaria

\section{Abstract}

This paper reports an exploratory study where a mixed methodology was used. Participants were $5^{\text {th }}$-grade students from a rural school. The main purpose of the study was to contribute to the pedagogical use of ICT in primary education through the inquiry on creative thinking and multimodal writing skills. The paper focuses on the presentation of results related to: a) the design and validation of an instrument for assessing creative thinking skills related to the writing of multimodal texts; b) the association between these two variables; $c$ ) the possibility of promoting this type of thinking in school, through intended, representative and cross-curricular digital writing activities.

Keywords

Creative thinking, multimodal writing, teaching, ICT, primary education

Resumo

0 estudo aqui apresentado é de caráter exploratório e foi desenvolvido a partir de uma metodologia mista com estudantes de quinto ano de uma instituição educativa rural. 0 propósito geral é contribuir ao uso pedagógico das TIC no ensino básico através da indagação das habilidades do pensamento criativo e a escrita de textos multimodais. 0 artigo visa especificamente apresentar os resultados relacionados com: a) a criação e validação da ferramenta para avaliar as habilidades do pensamento criativo associadas à escrita de textos multimodais; b) a associação que existe entre essas duas variáveis; e c) a possibilidade de potenciar esse tipo de pensamento na escola mediante atividades de escrita digital intencionadas, representativas e transversais ao currículo escolar.

\section{Palavras chave}

Pensamento criativo, escrita multimodal, didática, TIC, educação primaria

Artículo recibido el 20 de enero de 2016 y aprobado el 5 de agosto de 2016

1 Universidad de Antioquia, Medellín, Colombia. Correo electrónico: dora.chaverra@udea.edu.co.

2 Institución Educativa la Mosquita, Medellín, Colombia. Correo electrónico: claugirl21@gmail.com.

3 Artículo derivado de la investigación "Prácticas de escritura multimodal digital. Exploración de factores cognitivos, didácticos y socioculturales con estudiantes de Educación Básica Primaria", realizada entre febrero de 2013 y julio de 2015, financiada por el Comité para el Desarrollo de la Investigación (cooı) de la Universidad de Antioquia, Medellín (Colombia). 


\section{Introducción}

La utilización de las herramientas, aplicaciones o espacios de lectura y escritura disponibles por los medios y las TIC reivindican el papel protagónico que desempeñan en el campo de la alfabetización digital. Contrario a algunas percepciones apocalípticas en torno a su desaparición, su automatización o su remplazo por la tradición oral, exaltada a partir de la utilización de varias herramientas informáticas, el posicionamiento de la escritura y la lectura como habilidades lingüísticas, de pensamiento y comunicación es cada vez más fuerte (Chaverra, 2010).

En el campo educativo, más allá de las discusiones sobre las ventajas y desventajas que los entornos digitales le ofrecen a la enseñanza y el aprendizaje de un saber específico, su estatus social o las nuevas exigencias que plantea a las personas, el horizonte de análisis convendría dirigirlo hacia identificar de qué manera el uso de la tecnología está transformando los procesos y las prácticas. Reconocer la influencia de las Tic en los saberes, y explorar las prácticas de escritura multimodal, lleva necesariamente a pensar que en la escuela las propuestas didácticas no pueden orientarse de la manera como se ha hecho sin ellas; pero la reflexión apunta no solo a precisar cómo aprender o enseñar en entornos tecnológicos, sino para qué se hace, cuál es su dimensión formativa, y de qué manera esas condiciones transforman al sujeto mismo (Litwin, 1997). Las decisiones que orientan la política educativa al respecto, los criterios pedagógicos y didácticos asumidos en la escuela, la relación de los medios y las TIC con los saberes disciplinares, el fortalecimiento de competencias y habilidades, entre otros aspectos, requieren investigaciones que contribuyan al debate sobre la relación educación-TIC.

Incorporar las TIC en las aulas escolares y los procesos formativos de las instituciones educativas implica asumir y generar formas alternativas de promover los procesos de enseñanza y aprendizaje; lo que no puede traducirse en la metáfora que bien Dussel (2011) ha desarrollado, respecto a tener problemas viejos en odres nuevos. Se trata de buscar la manera de cumplir con los ideales de formación que retóricamente se explicitan, pero difícilmente se materializan en la práctica, relacionados con la generación de ambientes educativos donde el estudiante pueda ejercer control sobre su proceso formativo, proponer iniciativas de trabajo, dialogar con sus pares, confrontar sus ideas, unir esfuerzos, y de manera colaborativa, construir comprensivamente los conceptos y sus relaciones. Se trata de fortalecer las habilidades del pensamiento superior empleando las TIC, por tanto esta investigación se centra en indagar por las maneras de potenciar las habilidades del pensamiento creativo a través de la escritura de textos multimodales.

En un análisis más local del contexto investigativo asumido, se reconoce la existencia de políticas y programas educativos públicos colombianos, así como el entorno familiar e institucional de la comunidad educativa participante. Son aspectos que, unidos al desarrollo disciplinar, didáctico y pedagógico, contribuyen al estudio de los procesos de formación en la escuela para la toma de decisiones orientadas de un modo más comprensivo y menos prescriptivo y homogeneizador sobre el uso de TIC. Su integración en el currículo escolar y la práctica educativa, máxime en una zona rural, no puede limitarse a demandas externas, sino también a las necesidades de los estudiantes y las posibilidades de innovación de los procesos educativos. Tanto García-Valcárcel y Tejedor (2010) como Colom Gorgues (2004) aluden a la importancia del uso de las Tic en el ámbito rural como medio de equidad, además de ser una alternativa para disminuir la brecha digital con respecto a enclaves urbanos.

Los estudiantes colombianos han empezado a incorporar en sus hogares herramientas tecnológicas y las emplean para facilitar la comunicación y como apoyo a las consultas escolares; pero, como lo plantea Dussel (2011) la brecha digital se está desplazando del acceso a los usos, y ahora la nueva frontera se define por la capacidad de los usuarios de realizar operaciones complejas y aprovechar al máximo las posibilidades que ofrece la cultura digital. Por tanto, los estudiantes necesitan participar en procesos de alfabetización digital, y más aún aquellos que forman parte de la Educación Básica Primaria, de modo que les permitan reconocer sus intereses y necesidades 
al momento de leer, escribir e interactuar con los dispositivos tecnológicos, así como detectar sus dificultades para enfrentarse a diferentes dinámicas de trabajo cuando terminan el ciclo de la básica primaria e inician la transición al nivel de la secundaria.

Parte del proceso de alfabetización digital referido tiene una relación directa con la escritura de textos, bajo la convicción de que esta sigue siendo un proceso cognitivo, comunicativo y lingüístico presente y exigente en la formación de los estudiantes y las prácticas escolares mediadas por las Tic que las involucran. Esta convicción también reconoce la singularidad del proceso de composición de un texto digital, máxime uno de carácter multimodal. Este concepto se entiende desde la perspectiva de la semiótica social, que lo determina como un campo de estudio enfocado en la manera en que los seres humanos emplean las diferentes formas de comunicación -el habla, la escritura, la imagen, el gesto, el sonido- para representar o construir sentido del mundo (Stein, 2008). Los textos multimodales en medio digital serán estudiados como aquellos que poseen más de un modo de representación de las ideas, donde el significado se comunica a través de la sincronización, la concurrencia y la complementariedad (Farías, Obilinovic, Orrego, 2010; Walsh, 2006; ).

$\mathrm{Al}$ respecto, Edwards-Groves (2012) argumenta que "las habilidades fundamentales de la escritura no se reemplazan, pero se amplían para dar cuenta del cambio en las prácticas de aprendizaje que demanda la tecnología" (p. 101). En otras palabras, la escritura en el entorno digital y con características multimodales también es un proceso complejo porque, además de requerir el manejo técnico-instrumental de las herramientas o aplicaciones, exige una elaboración cuidadosa para articular los diferentes recursos semióticos y lograr comunicar eficazmente lo que se pretende con el texto.

\section{El pensamiento creativo en el ámbito digital}

La investigación científica sobre el pensamiento creativo se mantiene vigente para el siglo XXI al reconocer su importancia en la dinámica de la sociedad; de acuerdo con Celorrio (2003), aprender a pensar se convierte en una necesidad, y más aún que se aprenda a pensar de forma convergente y divergente. En efecto, cada vez se indaga más sobre los diferentes tipos de pensamiento que poseen los seres humanos (crítico, lógico, espacial, creativo, etc.) y se reconoce su importancia tanto a nivel científico como educativo. Al pensamiento creativo se le otorga atención, con mayor frecuencia, como factor importante para el progreso de un país y para afrontar los retos de la sociedad actual, globalizada y en constante cambio. Este tipo de pensamiento, según Blázquez (2009):

... con un buen enfoque pedagógico, debe ser un proceso cognitivo que se exprese, manifieste o materialice a través del descubrimiento, solución y/o formulación apropiada de problemas, la elaboración de productos y objetos originales, la generación de ideas valiosas, respuestas auténticas, acciones y hechos relevantes; encontrando nuevas combinaciones, relaciones novedosas y estrategias útiles para el contexto en que fueron creadas, partiendo de informaciones ya conocidas y facilitando el cambio en función del beneficio, el crecimiento y el desarrollo humano. (p. 7)

En este orden de ideas, fortalecer el pensamiento creativo se plantea como un componente importante de la formación que propende porque los estudiantes adquieran la capacidad para enfrentar una gran variedad de situaciones que exigen generar alternativas de solución, comunicar nuevas ideas, responder a diversas perspectivas planteadas; además, requiere del manejo efectivo de la información, el trabajo colaborativo, la toma de decisiones, la interacción y la producción de conocimientos, el cuidado del ambiente y el aprovechamiento de los recursos, entre otras finalidades. De acuerdo con Vizcaya (2010):

Es necesario estimular el pensamiento creativo en los estudiantes para la búsqueda de la verdad o el conocimiento, a través de procesos de descubrimiento y de investigación. De este modo, el estudiante como ciudadano se constituirá en un participante activo y en una persona crítica que intenta buscar las soluciones creativas y pertinentes a los problemas que se plantean en su entorno. (p. 95) 
El pensamiento creativo ha sido objeto de distintas investigaciones desde la década del cincuenta (Cachinero, 2007; Gómez, 2005; Guilford, 1950; Lacin y Balkan, 2010; Sternberg, 1988; Torrance, 1966, 1974; Wang, 2012); su manifestación es diversa en innumerables campos y en las actuaciones de la vida cotidiana. Los autores le han otorgado diferentes factores o habilidades; los más clásicos coinciden en señalar cuatro de ellas: fluidez, flexibilidad, originalidad y elaboración. Estas son asumidas y definidas en la presente investigación, atendiendo a las precisiones de Esquivias (2009), porque son susceptibles de ser transversales debido a la aplicabilidad que tienen en las diferentes áreas del conocimiento que estipula la Ley General de Educación colombiana (1994), el contexto educativo rural en el cual se lleva a cabo el estudio y su relación conceptual con la escritura de textos que incluye aspectos multimodales.

Al considerar las características acerca de las TIC y reconocer que el pensamiento creativo es aplicable a toda situación, no únicamente a un área específica del conocimiento, se crean, como lo plantean Manso, Pérez, Libedinsky, Light y Garzón (2011) "nuevas oportunidades para las comunidades escolares a través del uso creativo de la tecnología" (p. 86). La indagación de las cuatro habilidades del pensamiento creativo asociadas a la producción multimodal se genera a partir de actividades de escritura representativas acordes a los intereses de los estudiantes, su edad y su contexto. Siguiendo a Rendón (2003) se debe propiciar una atmósfera de libertad psicológica y de profundo humanismo, mediante una variedad de situaciones, las cuales pueden incluir el acercamiento a los problemas cotidianos de una manera innovadora, desde nuevas perspectivas.

Las habilidades del pensamiento creativo se pueden reflejar en las diversas acciones que realiza una persona o en los productos generados; por tanto, cuando se vinculan a la escritura multimodal digital es posible aprovechar las opciones que brinda este tipo de escritura, ya que facilita el diseño y el rediseño, en cualquier momento y lugar, permite el intercambio de ideas con otros sin importar su ubicación geográfica ni el tiempo. A la vez, puede resultar una tarea más compleja por cuanto no solo implica el saber procedimental sobre la herramienta o dispositivo tecnológico, sino que exige crear contenidos de calidad dado que la audiencia es amplia y heterogénea, debido a la competitividad y el alto flujo de información que circula en la sociedad. Ello demanda escribir con fluidez pero con precisión las ideas, saber modificar o enriquecer los textos producidos, ser flexibles ante las opiniones y sugerencias de los posibles revisores/lectores.

\section{Metodología}

El enfoque asumido en la investigación es de carácter mixto (Campos, 2009; Johnson, Onwuegbuzie y Turner, 2007) con un alcance exploratorio. El diseño se propone en cuatro fases, dos de ellas con un sentido secuencial, pero todas incluyen actividades y componentes particulares en su implementación: a) análisis del contexto teórico, familiar e institucional; b) diseño de una propuesta didáctica y de los instrumentos; c) trabajo de campo y procesamiento paralelo de información; y d) análisis de la información, socialización y divulgación de resultados. Los directivos de la institución educativa participante así como los docentes del nivel de básica primaria, los estudiantes y los padres de familia diligenciaron los consentimientos informados. Todos recibieron información sistemáticamente de los avances y resultados derivados del proceso.

Participaron cuarenta y cuatro (44) estudiantes de quinto grado de Educación Básica Primaria, matriculados en una institución educativa rural del departamento de Antioquia (Colombia). La mitad es del género femenino y en general, tienen edades que oscilan entre los nueve y los doce años. El trabajo de campo se lleva a cabo durante veinte semanas, equivalentes a dos períodos académicos del año escolar, con sesiones semanales de dos a tres horas cada una. A partir de una situación didáctica representativa y contextualizada, se realizan varias sesiones iniciando con la sensibilización del tema a través de lecturas, ejemplos, conversatorios y preguntas que 
activan los saberes previos, la imaginación y el pensamiento creativo; luego acciones que involucran explicaciones conceptuales y presentación de los propósitos por lograr; escritura del texto y, finalmente, realización de actividades de confrontación en diferentes modalidades orientadas a la revisión, reelaboración y edición final de los textos. Fueron diseñados cuatro instrumentos; para los fines del presente artículo, se reseña de manera particular el referido a la evaluación de las habilidades del pensamiento creativo.

\section{La evaluación de las habilidades del pensamiento creativo asociadas a la escritura de textos multimodales}

La descripción del diseño y la validación del instrumento utilizado para la evaluación de estas habilidades configuran un corpus de procedimientos que develan aspectos teóricos y metodológicos que forman parte de los resultados derivados del estudio realizado. El instrumento construido no solo es un medio, sino también un producto en el que confluyen la teoría, la experiencia de campo, la validación de expertos y el análisis estadístico, para su discusión tanto con la comunidad científica especializada como con los grupos académicos docentes.

A partir del análisis teórico reportado por la literatura sobre el pensamiento creativo y la escritura de textos multimodales, se definen las confluencias y divergencias entre ambos componentes. Forman parte de este corpus de revisión las pruebas diseñadas por Torrance $(1966,1974)$ para evaluar el pensamiento creativo en los componentes verbal y figurativo; la Prueba de Imaginación Creativa (PIC), enfocada en la fluidez de ideas, la flexibilidad del pensamiento, la originalidad de las producciones, la elaboración de las respuestas y el uso de detalles creativos de Artola, Ancillo, Mosteiro y Barraca (2004); y la escala para evaluar la calidad textual de producciones digitales de Chaverra (2013).

Esta validación teórica lleva a la construcción de una primera escala de observación de las habilidades, integrada por catorce indicadores que permiten descubrir y registrar las maneras en que los estudiantes efectúan sus procesos durante el desarrollo de las situaciones de escritura propuestas. Todos los estudiantes fueron observados durante dos o tres sesiones de trabajo diferentes. Al finalizar la aplicación de la escala de observación, se organizan los indicadores en orden descendente de recurrencia, de acuerdo a las acciones que fueron más evidenciadas en los estudiantes; y las observaciones registradas en las anotaciones adicionales se interpretan con base en los fundamentos teóricos extraídos de la revisión de la literatura.

El análisis de los datos obtenidos con la escala de observación deriva en dos aspectos. El primero, el establecimiento de una hipótesis emergente en términos de la existencia de una asociación, no solo conceptual sino también empírica, entre las habilidades del pensamiento creativo y la escritura de textos multimodales. El segundo, la creación del instrumento de evaluación. Este instrumento consta de dos componentes: una situación de escritura que demanda la producción de un texto descriptivoargumentativo y una escala compuesta por cinco (5) categorías y doce (12) indicadores para identificar y analizar la información derivada de la producción de cada estudiante.

El instrumento se sometió a un proceso de validación mediante el juicio de dos expertos con alto nivel de formación educativa y experiencia investigativa afín al campo en el que se inscribe el estudio. Así mismo, se probó la confiabilidad mediante el Alfa de Cronbach $(0,8)$ y la consistencia interna de la escala con la correlación ítem-total. Los resultados muestran que la mayoría de indicadores se correlacionan de manera positiva y significante con una media de 0,235 , además la correlación entre cada indicador y la habilidad de pensamiento creativo se encuentran entre 0,328 y 0,669 , lo que indica un buen tipo de asociación lineal. La tabla 1 resume los datos de este proceso. 
Universidad Pedagógica Nacional

Facultad de Humanidades

Tabla 1. Correlación ítem-total-habilidad de pensamiento creativo

\begin{tabular}{|c|c|c|}
\hline Indicador & Correlación & P-Valor \\
\hline $\begin{array}{l}1.1 \text { Integra varias imágenes (las superpone) para } \\
\text { reforzar el significado de sus ideas. }\end{array}$ &, $607^{*}$ & ,000 \\
\hline $\begin{array}{l}\text { 1.2 Presenta gran cantidad y calidad de información (ideas) en } \\
\text { su texto, es decir que contiene más de } 6 \text { ideas diferentes, sin } \\
\text { redundancias, bien redactadas y coherentes con el tema tratado. }\end{array}$ &, $597^{*}$ & ,000 \\
\hline $\begin{array}{l}\text { 2.1 Usa efectos para las imágenes (formato de imagen: bordes, forma, } \\
\text { sombreado, animaciones) para enfatizar lo que quiere expresar. }\end{array}$ & ,650* & ,000 \\
\hline $\begin{array}{l}2.2 \text { Usa efectos de fuente (negrita, cursiva, subrayado, cambio } \\
\text { de color o tamaño) para resaltar alguna(s) idea(s) en su texto. }\end{array}$ &, $665^{*}$ & ,000 \\
\hline 2.3 Emplea un vocabulario variado y acorde al tema que desarrolla. & ,432* & ,000 \\
\hline $\begin{array}{l}\text { 2.4 Manifiesta, en su texto, una misma idea a través } \\
\text { de diferentes modos de representación (imagen, audio, } \\
\text { video, mapas, gráficos, código alfabético). }\end{array}$ &, $580^{*}$ & ,000 \\
\hline $\begin{array}{l}\text { 3.1 Emplea varias imágenes relacionadas con el tema, ya sea para } \\
\text { explicar, complementar o ejemplificar la información de su texto. }\end{array}$ & ,389* & ,000 \\
\hline $\begin{array}{l}\text { 3.2 Relaciona de manera adecuada el título y } \\
\text { el contenido en el texto elaborado. }\end{array}$ & ,397* & ,000 \\
\hline $\begin{array}{l}3.3 \text { Incluye grabaciones de voz (audios) o videos de acuerdo al } \\
\text { tema que desarrolla para enriquecer la presentación de su texto. }\end{array}$ & ,328* & ,000 \\
\hline $\begin{array}{l}\text { 3.4 Utiliza colores (en el diseño, en la letra y demás elementos de su } \\
\text { presentación) que contrastan adecuadamente en el texto producido. }\end{array}$ &, $588^{*}$ & ,000 \\
\hline $\begin{array}{l}\text { 4.1 Combina de manera coherente y novedosa tres o más modos } \\
\text { de representación (imagen fija, imagen en movimiento, audio, } \\
\text { colores, video, mapas, dibujos y código alfabético) en su texto. }\end{array}$ & ,669* & ,000 \\
\hline $\begin{array}{l}\text { 4.2 Emplea diseños y efectos (animaciones o transiciones) } \\
\text { variados para mejorar la presentación de su texto. }\end{array}$ &, $541^{*}$ & ,000 \\
\hline
\end{tabular}

La validez de la escala se evaluó mediante análisis factorial. En todas las pruebas se consideró una diferencia como significativa si el valor $p$ era menor que el nivel de significación $\alpha=0,05$. La validez discriminante mediante análisis factorial mostró una adecuada capacidad discriminante con todos los coeficientes entre 0,271 y 0,694 (KMO = 0,766), adicionalmente se rechazó la hipótesis de esfericidad. 


\section{Resultados}

La producción escrita multimodal realizada por cada estudiante con base en la situación de escritura propuesta es valorada por dos evaluadoras externas y la docente-investigadora, utilizando la escala diseñada para tal fin. Cada indicador dentro del instrumento fue valorado en escala dicotómica, 1 si se presenta en el texto la acción que se describe en cada indicador, 0 si no se presenta en el texto la acción que se describe. Posteriormente, se construye una nueva variable que permita realizar comparaciones puesto que la cantidad de indicadores no es la misma en todas las habilidades y esto puede influir en el resultado si se usa la suma como estimación de la prevalencia del indicador. La nueva escala procura llevar las puntuaciones a una escala de 0 a 100 , de modo que las comparaciones sean posibles, utilizando la fórmula (1):

Nueva escala $=\left(\frac{\text { Puntuación Observada }}{\text { Puntuación } \text { Ideal }}\right) \times 100$

\section{Donde}

Puntuación observada corresponde al conteo o la suma de puntuaciones 1 (evidencia el indicador de la categoría analizada) resultado de la valoración dada en cada prueba por el evaluador.

Puntuación ideal es la suma de las puntuaciones máximas posibles si el estudiante presenta evidencia de poseer el indicador analizado en todas las pruebas. Por ejemplo, la puntuación ideal sería doce (12), correspondiente a encontrar evidencia en todos los indicadores de la acción analizada.

En la tabla 2 se presentan los resultados de las valoraciones realizadas, incluyendo la variable sexo. $\mathrm{Si}$ bien los datos muestran una marcada tendencia positiva de las niñas hacia los procesos creativos $(70,4)$, siendo el aspecto más diferenciador la flexibilidad $(77,8)$ y la originalidad $=67,7)$, lo relevante de los resultados es la evidencia de la asociación existente entre las dos variables en los procesos de enseñanza y aprendizaje, independientemente del género.

Tabla 2. Valoración por evaluador y sexo de la habilidad de pensamiento creativo

\begin{tabular}{|c|c|c|c|c|c|c|}
\hline & \multirow{2}{*}{$\begin{array}{l}\text { Evaluación } \\
\text { general }\end{array}$} & \multicolumn{3}{|c|}{ Evaluador } & \multicolumn{2}{|c|}{ Sexo } \\
\hline & & $\begin{array}{l}\text { Profesor1 } \\
\text { Profesor4 }\end{array}$ & $\begin{array}{l}\text { Profesor } 2 \\
\text { Profesor } 5\end{array}$ & $\begin{array}{l}\text { Profesor } 3 \\
\text { Profesor } 6\end{array}$ & Masculino & Femenino \\
\hline $\begin{array}{c}\text { Habilidad pensamiento } \\
\text { creativo }\end{array}$ & 65,12 & 78,49 & 50,19 & 66,67 & 60,23 & 70,24 \\
\hline 1. Fluidez & 55,04 & 88,37 & 26,74 & 50,00 & 50,00 & 60,32 \\
\hline $\begin{array}{l}1.1 \text { Integra varias imágenes } \\
\text { (las superpone) para reforzar } \\
\text { el significado de sus ideas. }\end{array}$ & 44,96 & 95,35 & 2,33 & 37,21 & 43,94 & 46,03 \\
\hline $\begin{array}{l}1.2 \text { Presenta gran cantidad y } \\
\text { calidad de información (ideas) en } \\
\text { su texto, es decir que contiene } \\
\text { más de } 6 \text { ideas diferentes, sin } \\
\text { redundancias, bien redactadas y } \\
\text { coherentes con el tema tratado. }\end{array}$ & 65,12 & 81,40 & 51,16 & 62,79 & 56,06 & 74,60 \\
\hline 2. Flexibilidad & 72,67 & 83,72 & 54,65 & 79,65 & 67,80 & 77,78 \\
\hline $\begin{array}{l}2.1 \text { Usa efectos para las } \\
\text { imágenes (formato de imagen: } \\
\text { bordes, forma, sombreado, } \\
\text { animaciones) para enfatizar } \\
\text { lo que quiere expresar. }\end{array}$ & 64,34 & 69,77 & 53,49 & 69,77 & 51,52 & 77,78 \\
\hline
\end{tabular}


Universidad Pedagógica Nacional

Facultad de Humanidades

\begin{tabular}{|c|c|c|c|c|c|c|}
\hline $\begin{array}{l}2.2 \text { Usa efectos de fuente } \\
\text { (negrita, cursiva, subrayado, } \\
\text { cambio de color o tamaño) } \\
\text { para resaltar alguna(s) } \\
\text { idea(s) en su texto. }\end{array}$ & 65,89 & 83,72 & 32,56 & 81,40 & 57,58 & 74,60 \\
\hline $\begin{array}{c}2.3 \text { Emplea un vocabulario } \\
\text { variado y acorde al tema } \\
\text { que desarrolla. }\end{array}$ & 79,07 & 93,02 & 69,77 & 74,42 & 77,27 & 80,95 \\
\hline $\begin{array}{l}\text { 2.4 Manifiesta, en su texto, } \\
\text { una misma idea a través } \\
\text { de diferentes modos de } \\
\text { representación (imagen, } \\
\text { audio, video, mapas, gráficos, } \\
\text { código alfabético). }\end{array}$ & 81,40 & 88,37 & 62,79 & 93,02 & 84,85 & 77,78 \\
\hline 3. Elaboración & 65,31 & 70,93 & 53,49 & 71,51 & 61,36 & 69,44 \\
\hline $\begin{array}{l}\text { 3.1 Emplea varias imágenes } \\
\text { relacionadas con el tema, } \\
\text { ya sea para explicar, } \\
\text { complementar o ejemplificar } \\
\text { la información de su texto. }\end{array}$ & 92,25 & 95,35 & 88,37 & 93,02 & 96,97 & 87,30 \\
\hline $\begin{array}{l}3.2 \text { Relaciona de manera } \\
\text { adecuada el título y el contenido } \\
\text { en el texto elaborado. }\end{array}$ & 86,82 & 93,02 & 81,40 & 86,05 & 78,79 & 95,24 \\
\hline $\begin{array}{l}3.3 \text { Incluye grabaciones } \\
\text { de voz (audios) o videos } \\
\text { de acuerdo al tema que } \\
\text { desarrolla para enriquecer la } \\
\text { presentación de su texto. }\end{array}$ & 10,85 & 11,63 & 9,30 & 11,63 & 4,55 & 17,46 \\
\hline $\begin{array}{l}3.4 \text { Utiliza colores (en el } \\
\text { diseño, en la letra y demás } \\
\text { elementos de su presentación) } \\
\text { que contrastan adecuadamente } \\
\text { en el texto producido. }\end{array}$ & 71,32 & 83,72 & 34,88 & 95,35 & 65,15 & 77,78 \\
\hline 4. Originalidad & 59,69 & 73,26 & 58,14 & 47,67 & 53,03 & 66,67 \\
\hline $\begin{array}{l}4.1 \text { Combina de manera } \\
\text { coherente y novedosa tres o } \\
\text { más modos de representación } \\
\text { (imagen fija, imagen en } \\
\text { movimiento, audio, colores, } \\
\text { video, mapas, dibujos y código } \\
\text { alfabético) en su texto. }\end{array}$ & 41,09 & 65,12 & 32,56 & 25,58 & 31,82 & 50,79 \\
\hline $\begin{array}{l}\text { 4.2 Emplea diseños y efectos } \\
\text { (animaciones o transiciones) } \\
\text { variados para mejorar la } \\
\text { presentación de su texto. }\end{array}$ & 78,29 & 81,40 & 83,72 & 69,77 & 74,24 & 82,54 \\
\hline
\end{tabular}

El análisis detallado de los datos a partir de la generación de una matriz de correlación de las habilidades muestra que la flexibilidad y la elaboración tuvieron una relación más estrecha con la escritura de los textos multimodales ( $\rho=0.898$ y $\rho=0,786$, respectivamente). 
Ahora bien, se utilizó la información obtenida a partir de los cuartiles de la variable para generar una clasificación general de los estudiantes, según los resultados en la prueba, tal como se presenta en la tabla 3. Más que medir el rango, se trata de identificar grupos que muestren las posibilidades de potenciar dichas habilidades con propuestas intencionadas en la escuela.

Tabla 3. Clasificación general de los estudiantes según los resultados de la prueba

\begin{tabular}{|l|l|}
\hline \multicolumn{1}{|c|}{ Nombre } & \multicolumn{1}{c|}{ Categorías } \\
\hline $\begin{array}{l}\text { Fluidez } \\
\text { Flexibilidad }\end{array}$ & $\begin{array}{l}\text { Intervalo* } \\
\text { De } 0 \text { a } 25 \text { bajo }\end{array}$ \\
\hline $\begin{array}{l}\text { Elaboración } \\
\text { Originalidad }\end{array}$ & De 26 a 50 bajo-medio \\
$\begin{array}{l}\text { Habilidad pensamiento } \\
\text { creativo }\end{array}$ & De 51 a 75 medio-alto \\
\hline
\end{tabular}

Los resultados globales de la escala (véase la figura 1), muestran que los estudiantes se ubican en un nivel medio-alto en las habilidades evaluadas. Ello indica, además de la existencia de la relación señalada previamente, las posibilidades de potenciar dichas habilidades a partir de situaciones didácticas.

Figura 1. Resumen general de los resultados de la habilidad del pensamiento creativo y sus componentes

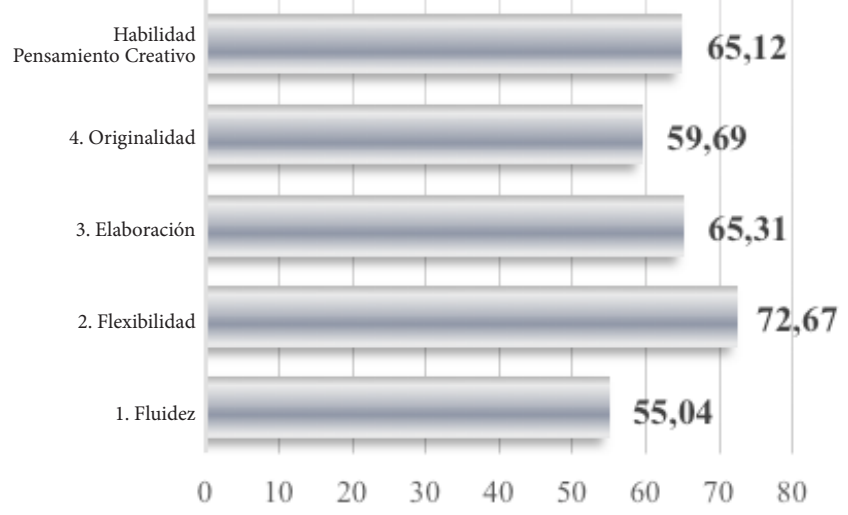

La flexibilidad, asumida en este estudio como la habilidad para considerar diferentes puntos de vista y presentar respuestas alternas o variedad de respuestas, aparece con la mayor puntuación, lo cual demuestra la variación de esta habilidad cuando está asociada a la escritura de textos multimodales. Este resultado contrasta con la investigación presentada por Wang (2012), quien exploró la relación del pensamiento creativo con la lectura y la escritura, en la cual la flexibilidad, entendida como la variedad de ideas utilizas para resolver problemas, obtuvo una de las puntuaciones más bajas con respecto a las otras habilidades evaluadas. Por otro lado, en el estudio de Wang (2012), es la capacidad de elaboración la que presenta una diferencia más notable en el rendimiento creativo, por lo cual argumenta que la lectura y la escritura tienen una relación positiva con la capacidad de enriquecer ideas originales con detalles. En el presente estudio, la habilidad de elaboración es la segunda en evidenciar una mayor asociación, por lo cual se puede inferir que tanto con los hábitos de lectura y escritura como con la producción de textos multimodales se lograría potenciar en mayor medida esta habilidad, al presentar una relación más positiva con estas actividades.

En la habilidad de la fluidez, de acuerdo a los indicadores utilizados, se hizo referencia no solo a la cantidad de la información o ideas expresadas en el texto sino también a su calidad. Por tanto, más que la cantidad de imágenes que el estudiante empleaba en su texto, se valoró su habilidad para integrarlas como parte del significado de sus ideas. Igualmente, para el código alfabético se valora además de la cantidad, aspectos de calidad: ideas diferentes, sin redundancias, bien redactadas y coherentes con el tema tratado. Estas acciones le demandan mayor exigencia al estudiante puesto que implican una habilidad subyacente para revisar sus textos y corregirlos, es decir, autoevaluarse y autocorregirse.

La originalidad, según los indicadores de la escala, exige del estudiante un mayor nivel de dedicación, conocimientos y capacidad para trabajar de modo independiente, así como articular los modos de representación simbólica en forma armoniosa, estableciendo relaciones lejanas o poco convencionales entre estos.

Cuanto más se incorporen diferentes alternativas de visualización, se empleen más efectos en la representación de ideas y haya mayor nivel de experimentación del estudiante en la presentación del contenido, mayores serán las posibilidades de fortalecer su habilidad creativa en la escritura de textos multimodales. 
Los resultados obtenidos en este estudio demuestran el cumplimiento de la hipótesis emergente, constituyen una evidencia empírica sobre la asociación entre las habilidades del pensamiento creativo y la escritura de textos multimodales, y en efecto, sobre las posibilidades de potenciar este tipo de pensamiento en la escuela mediante esta modalidad de escritura que a la vez fomenta el uso intencionado y representativo de las TIC.

Gómez (2005) plantea que los campos utilizados para el fomento de la creatividad han sido el área artística y la resolución de problemas en matemáticas, pero también resalta que la experiencia en algunos centros educativos demuestra que es factible trabajar la creatividad desde cualquier área de conocimiento, una premisa consistente con los resultados del presente estudio por cuanto las situaciones de escritura fueron articuladas con las áreas curriculares básicas.

\section{Conclusiones}

La comprensión de los elementos expuestos contribuye al debate sobre los prejuicios existentes entre los defensores y detractores del uso de las TIC en educación. En el caso del primer grupo, las razones están asociadas a la percepción de las Tic como solución a todas las dificultades de la enseñanza y el aprendizaje; el logro de un aprendizaje de orden superior mediante su uso; el acceso espontáneo a maneras innovadoras y rápidas de escribir. En el caso del segundo grupo, algunas de las premisas defendidas manifiestan la automatización de los procesos académicos; el almacenamiento y procesamiento técnico de información; la obstaculización del aprendizaje; y el uso indiferenciado entre información y conocimiento, lo que repercute en aprendizajes efímeros y superficiales. Referirse a la integración de las TIC en el ámbito educativo, particularmente desde una perspectiva didáctica vinculada a los procesos de enseñanza y aprendizaje, significa asumir una postura analítica, reflexiva, flexible y participativa en la cual la relación bidireccional, no subordinada, entre las TIC y la escuela, esté permeada por la perspectiva del uso y la necesidad.
$\mathrm{Al}$ respecto, conviene retomar la perspectiva de integración de Díaz (2010), quien diferencia el uso pragmático de las Tic entendido como el uso de "... artefactos tecnológicos que permiten mayor eficiencia en lo que se hace, sobre todo la recuperación u organización de cúmulos de contenidos de información” y el uso epistémico de las TIC, asumido como "... herramientas de la mente, enfocadas a pensar e interpretar, a construir conocimiento en colaboración" (p. 138). En ambos casos, los factores de orden cognitivo, actitudinal, logístico, experiencial, contextual, cultural y técnico se convierten en determinantes de los procesos de integración y por tanto, resulta necesario tenerlos en cuenta. En esencia, cualquiera que sea el escenario de integración de las Tic, requiere hacer mucho más visible el aprendizaje que los artefactos, aplicaciones, dispositivos o programas utilizados.

Los resultados de la investigación constituyen una evidencia empírica, no solo teórica, de la relación existente entre las habilidades del pensamiento creativo y la producción de textos multimodales en relación con los procesos de enseñanza y aprendizaje en el ámbito escolar. Esta correlación se puede traducir en un argumento pedagógico y didáctico para la definición de criterios que superan la dimensión instrumental del uso de los medios y las TiC en la escuela, exigiendo procesos más comprensivos, reflexivos y complejos durante la generación de propuestas didácticas.

En razón a las características del estudio, no se busca formular generalizaciones; esta no fue la pretensión inicial dado su carácter exploratorio. No obstante, los hallazgos presentados señalan tendencias importantes relacionadas con: a) la interrelación de los procesos cognitivos (pensamiento, escritura) con el uso de los medios y las TIC para propósitos educativos; b) el papel de los aspectos contextuales, institucionales, disciplinares y pedagógicos en la generación de procesos de enseñanza y aprendizaje intencionados a través de las propuestas didácticas de aula con carácter transversal al currículo escolar (Delgado, 2006; Johnson, 2003); c) la necesidad de generar mayores investigaciones sobre las prácticas 
de escritura en el ámbito digital, cuya base conceptual y empírica contribuya a la formación docente y a la generación de programas de intervención orientados a la materialización de las políticas educativas que buscan articular las Tic en la educación.

Finalmente, los resultados permiten pensar en que es posible potenciar este tipo de pensamiento en la escuela mediante actividades de escritura multimodal. Un primer criterio para ello, es su concepción como proceso (no es un acto espontáneo), por tanto las iniciativas orientadas hacia tal fin deben considerar la flexibilidad en el tiempo que toman las actividades de producción; la escuela por sus múltiples responsabilidades privilegia el hacer sobre el pensar, situación que podría ser paradójica pero que en la práctica se traduce en la acumulación de actividades en detrimento de su calidad. Una percepción afín a los planteamientos de Lacin y Balkan (2010) para quienes las tareas involucradas con el pensamiento creativo requieren grandes períodos de solución.

Un segundo criterio por considerar es la inclusión de situaciones y actividades que impliquen un reto para los estudiantes. De acuerdo con Galvis (2013), diseñar propuestas que generen desequilibrios y demanden altos niveles de pensamiento productivo, más que reproductivo. Un tercer criterio, la vinculación de la realidad e intereses de los estudiantes al trabajo propuesto. Siguiendo a Dewey (1989):

\section{... únicamente cuando las cosas que nos rodean tienen sentido para nosotros, únicamente cuando significan consecuencias a las que se puede llegar utilizándolas de tal o cual manera, únicamente entonces se da la posibilidad de control deliberado e intencional de las mismas. (p. 34)}

La escritura ofrece un amplio campo de posibilidades y más aún cuando se produce en el medio digital, pues facilita y estimula el uso de diversos modos de representación para que los estudiantes construyan y expresen sus ideas y los conceptos que logran estructurar; aunque se puede tornar en una tarea más compleja debido a que se requiere desarrollar las habilidades para integrar estos recursos semióticos de manera coherente y novedosa lo cual implica, más que destreza en el manejo técnico de las TIC, el desarrollo del pensamiento creativo, un proceso que necesariamente responde a acciones intencionadas y planificadas si se pretende transformar la escuela como agente principal en la formación de las nuevas generaciones (Barba y García, 2006). En esta línea de ideas, Stone (2006) asevera que los ciudadanos deben aprender cómo generar nuevo conocimiento y cultivar hábitos que permitan el aprendizaje continuo, la reflexión y las acciones responsables, razón por la cual se debe ayudar a los estudiantes a construir comprensiones, realidades que incluyan la capacidad y disposición de desarrollar y aplicar el conocimiento de manera creativa, flexible y apropiada en situaciones variadas. Para ello se requiere fortalecer las competencias en el uso de las TIC, es decir, se necesita de un proceso de alfabetización digital que implica, no solo obtener el acceso a comunicaciones, la capacidad de analizar, cuestionar y reflexionar de un modo crítico la información que se recibe a través de los medios, sino también saber escribirlos, además de leerlos; implica la producción creativa en los nuevos medios (Buckingham, 2008).

\section{Referencias bibliográficas}

Artola, T.; Ancillo, I.; Mosteiro, P. y Barraca, J. (2004). PIC. Prueba de imaginación creativa. Madrid: TEA.

Barba, M. y García, M. (2006). La creatividad y su valor educativo. Revista E-Curriculum.1(2), 1-10.

Blázquez, A. (2009). Educación y creatividad. Revista digital Innovación y Experiencias Educativas, 14. Recuperado de http://www.csi-csif.es/andalucia/ modules/mod_ense/revista/pdf/Numero_14/ANTONIO_BLAZQUEZ_1.pdf

Buckingham, D. (2008). Más allá de la tecnología. Aprendizaje infantil en la era de la cultura digital (cap. 8). Buenos Aires: Manantial.

Cachinero, A. (2007). Una experiencia de entrenamiento del pensamiento creativo en alumnos de $2^{\circ}$ ciclo de Educación Primaria. Psicología Educativa, 13(1) (pp. 79-91). 
Campos, A. (2009). Métodos mixtos de investigación. Integración de la investigación cuantitativa y la investigación cualitativa. Bogotá: Cooperativa Editorial Magisterio.

Celorrio, R. (2003). Desarrollo del pensamiento creativo en la Eso. Revista de Ciencias de la Educación, 196, 433-466.

Chaverra, D. (2010). Los procesos de enseñanza y aprendizaje de la lectura y la escritura en el marco de la alfabetización digital. Revista Lenguaje y Escuela, 7, 97-108.

Chaverra, D. (2013). La producción de textos digitales con estudiantes de Educación Básica Primaria. Aspectos conceptuales y metodológicos resultados de la investigación en el aula. En Memoria Xvi Congreso Internacional Edutec 2013: "Educación y tecnología: una oportunidad para impulsar el desarrollo", San José de Costa Rica, 6 y 7 de noviembre.

Colom Gorgues, A. (2004). Innovación organizacional y domesticación de internet y las TIC en el mundo rural, con nuevas utilidades colectivas y sociales. La figura del Telecentro y el Teletrabajo. Revista de Economía Pública, Social y Cooperativa, 49, 77-116.

Delgado, A. (2006). Guía para el desarrollo del pensamiento creativo. República del Perú. Ministerio de Educación.

Dewey, J. (1989). Cómo pensamos. Nueva exposición de la relación entre pensamiento reflexivo y proceso educativo (pp. 33-45, 47-61, 63-73). Barcelona: Paidós.

Díaz, F. (2010). Integración de las Tic en el currículo y la enseñanza para promover la calidad educativa y la innovación. Pensamiento Iberoamericano, Revista de Economía Política, 7, 129-149.

Dussel, I. (2011). ¿Vino viejo en odres nuevos? Debates sobre los cambios en las formas de enseñar y aprender con nuevas tecnologías En Aprender y enseñar en la cultura digital. Memorias vi Foro Latinoamericano de Educación. Educación y nuevas tecnologías: los desafíos pedagógicos ante el mundo digital (pp. 1-32). Buenos Aires: Santillana. Recuperado de http:// portal.educ.ar/noticias/documento $\% 20$ basico $\% 20$ dussel\%20VII\%20foro.pdf

Edwards-Groves, C. (2012). Interactive Creative Technologies: Changing learning practices and pedagogies in the writing classroom. Australian Journal of Language and Literacy, 35(1), 99-113.

Esquivias, M. (2009). Análisis del pensamiento creativo en estudiantes universitarios: expresión lingüística.
UNAM-Facultad de Filosofía y Letras. x Congreso Nacional de Investigación Educativa, Veracruz. Recuperado de http://www.comie.org.mx/congreso/ memoriaelectronica/v10/pdf/area_tematica_01/ ponencias/0639-F.pdf.

Farías, M.; Obilinovic, K. y Orrego, R. (2010). Modelos de aprendizaje multimodal y enseñanza-aprendizaje de lenguas extranjeras. UT. Revista de Ciències de l'Educación (pp. 55-74).

Galvis, A. (2013). Ambientes educativos CLIC -creativos, lúdicos, interactivos y colaborativos- para aprender en la era de la información. Bogotá: Universidad de los Andes, Centro de Investigación y Formación en Educación (CIFE).

García-Valcárcel, A. y Tejedor, F. (2010). Evaluación de procesos de innovación escolar basados en el uso de las Tic desarrollados en la Comunidad de Castilla y León. Revista de Educación, 352, 125-147.

Gómez, J. (2005). Educación y creatividad. Publicaciones de la Universidad de Navarra. Estudios sobre Educación, 9, 79-105.

Guilford, J. (1950). Creativity. American Psychologist, 5, 444-454.

Johnson, A. (2003). El desarrollo de las habilidades de pensamiento: aplicación y planificación para cada disciplina. México: Pax.

Johnson, R. B.; Onwuegbuzie, A. y Turner, L. (2007). Toward a definition of mixed methods research. Journal of Mixed Methods Research 1(2), 112-133. Recuperado de http://www.sagepub.com/bjohnsonstudy/articles/Johnson,\%20Burke\%20Mixed\%20 Methods\%20Research.pdf.

Lacin, C. y Balkan, F. (2010). How much science and technology lesson student studying books support creative thinking? Science Teaching. Procedia Social and Behavioral Sciences, 2(2), 2105-2110.

Ley General de Educación-Ley 115 de 1994. (1994). Bogotá: Ministerio de Educación Nacional.

Litwin, E. (1997). Las configuraciones didácticas. Buenos Aires: Paidós.

Manso, M.; Pérez, P.; Libedinsky, M.; Light, D. y Garzón, M. (2011). Las Tic en las aulas. Experiencias Latinoamericanas. Buenos Aires: Paidós.

Rendón U., M. A. (2003). El desarrollo de la creatividad en el preescolar. Disponible en: http://www. creatividadcursos.com/recrearte/IMG/pdf/R11__2.J_-_El_desarrollo_de_la_creatividad_en_el_preescolar._Maria_A._Rendon.pdf 
Stein, P. (2008). Multimodal Instructional Practices. En J. Coiro, M. Knobel, C. Lankshear y D. Leu. Handbook of Research on New Literacies (pp. 871-898). Nueva York: Lawrence Erlbaum.

Sternberg, R. (1988). The nature of creativity: Contemporary psychological perspectives. Nueva York: Cambridge University Press.

Stone, M. (2006). “Teaching for meaningful learning with new technologies". En E. A. Ashburn y R. E. Floden (eds.). Meaningful learning using technology: What educators need to know and do? Nueva York: Teachers College Columbia University Press.

Torrance, P. (1966). Torrance Tests of creative thinking: Norms Technical Manual. Princeton, Nueva Jersey: Personnel Press.

Torrance, P. (1974). The Torrance tests of creative thinking. Manual and Scoring Guide: Verbal tests A, figural test. Lexington, KY: Ginn.

Vizcaya, M. (2010). Concepción pedagógica creativa fundamentada en la teoría crítica educativa de Pablo Freire. Educare, 14(1), 93-117.

Walsh, M. (2006). Multimodal literacy: What does it mean for classroom practice? Australian Journal of Language and Literacy, 33(3), (211-239).

Wang, A. (2012). Exploring the relationship of creative thinking to reading and writing. Thinking Skills and Creativity, 7, (38-47). 